\title{
Media portrayal of non-invasive prenatal testing: a missing ethical dimension
}

\author{
Kalina Kamenova, Vardit Ravitsky, Spencer McMullin \\ and Timothy Caulfield
}

\begin{abstract}
Non-invasive prenatal testing (NIPT) is an emerging technology for detecting chromosomal disorders in the fetus and mass media may have an impact on shaping the public understanding of its promise and challenges. We conducted a content analysis of 173 news reports to examine how NIPT was portrayed in English-language media sources between January 1 and December 31, 2013. Our analysis has shown that media emphasized the benefits and readiness of the technology, while overlooking uncertainty associated with its clinical use. Ethical concerns were rarely addressed in the news stories, which points to an important dimension missing in the media discourse.
\end{abstract}

Keywords

Health communication; Representations of science and technology

Context

The years since the discovery of cell-free fetal DNA (cffDNA) in maternal plasma in 1997 have seen significant advances in the field of non-invasive prenatal testing (NIPT). These tests use cell-free fragments of fetal DNA obtained from maternal plasma for early detection of chromosomal aneuploidies, such as trisomies 13, 18, and 21, and other genetic conditions, without posing an increased risk of miscarriage [Levine and Goldschlag, 2014; Bianchi et al., 2014]. MaterniT21 was the first commercially available test for trisomy 21 detection launched in the United States in 2011 by the U.S.-based company Sequenom, Inc. It was followed by MaterniT21 PLUS in 2012 which can diagnose trisomies 21, 13 and 18, as well as fetal sex aneuploidies, trisomies 16, 22, fetal sex and select microdeletions.

Commercial NIPT have since become widely available and research in the field has been primarily driven by the commercial sector [Morain, Greene and Mello, 2013; Agarwal et al., 2013; Chitty and Bianchi, 2013]. In Canada, for example, NIPT is presently available through the private sector in the Province of British Columbia [Perinatal Services BC, 2014] and through the publicly funded health care system in the Province of Ontario [CHEO, 2014].

Recent advances in massively parallel sequencing (MPS) promise to extend the use of the technology for screening of sub-chromosomal aberrations, monogenetic disorders, and potentially even the whole-genome sequencing of the human fetus [Kitzman et al., 2012; Fan et al., 2012]. Given the current state of the science, NIPT is 
recommended for use as a second-tier screening tool for women identified as having high risk of aneuploidy [Langlois et al., 2013; Wilson et al., 2013]. There are expectations that the technology will soon become accurate enough to replace current screening methods and diagnostic tests [Norton, Rose and Benn, 2013; Oepkes et al., 2014], as well as predictions that it will be established a new standard of care for prenatal screening [Levine and Goldschlag, 2014]. This would entail numerous benefits, such as eliminating the increased risk of miscarriage associated with invasive tests (e.g., amniocentesis), allowing access to results earlier in the pregnancy, and possibly lowering healthcare expenditure [Song, Musci and Caughey, 2013; Beulen et al., 2014].

While NIPT carries great potential for the field of prenatal care, it also poses some difficult ethical and policy questions about the boundaries of its application and how it can best be implemented in the healthcare system [King, 2012; Caulfield, 2014]. NIPT also raises numerous ethical, social and legal challenges [Greely, 2011; Dickens, 2014]. The emerging - and fast growing — academic literature that explores these issues has articulated five broad categories of concerns. First, there are concerns stemming from the potential routine use of NIPT in prenatal care and the threats this routinization may pose to reproductive autonomy. In the absence of risk to the pregnancy, clinicians may see counseling and informed consent as less important than for invasive testing [van den Heuvel et al., 2010; Deans and Newson, 2011; Hill et al., 2013], as is currently the case regarding non-invasive screening tests [Seavilleklein, 2009; Kellogg et al., 2014]. Routinization may also increase pressure on women to test, thus limiting - rather than promoting - their liberty to choose [Lewis, Silcock and Chitty, 2013]. Second, there are additional concerns stemming from the increase in the volume of testing. Once NIPT is offered to all pregnant women, it will increase the rate of detection of chromosomal aneuploidies and other genetic conditions in the fetus and subsequently the rate of termination of affected pregnancies [King, 2012; van Schendel et al., 2014]. This, in turn, will further reduce the number of individuals living with Down syndrome and other conditions in our society. Such changes may affect social diversity and increase stigmatization and discrimination against disabled individuals and their families [Kaposy, 2013], while negatively impacting available support systems and research efforts to find cures [Parens and Asch, 1999; King, 2011]. Third, there are concerns that lowering the threshold of appropriate testing through NIPT may lead to potential abuses of the technology for selecting sex and other non-medical traits. This is seen as potentially having eugenic implications and promoting the pursuit of 'perfect babies' [Skirton and Patch, 2013]. This concern is not merely hypothetical. Historically pre-natal screening has been routinely used for sex selection and has contributed to widespread gender discrimination in developing nations such as India, China and Brazil, but also in developed countries such as the U.S.A. and Hungary [Wertz and Fletcher, 1993; George, 2006]. Fourth, the cost of NIPT and the fact that it is entering the healthcare system through the private market raise concerns about just and equitable access to the test [Agarwal et al., 2013]. The final set of considerations includes legal arguments regarding the current trend of patenting NIPT technologies as limiting access to the test [Norton, Rose and Benn, 2013], as well as the possible liability of clinicians who do not offer NIPT to pregnant women and their exposure to 'wrongful life' or 'wrongful birth' claims [Toews and Caulfield, 2014]. 
This brief overview of recent studies on the topic clearly highlights the complexity of ethical, social, and legal issues (ELSI) associated with the development of NIPT. Given the growing popularity of this new genetic testing technology, it is also important to scrutinize how the test and its attributes have been portrayed in the popular discourse, particularly whether media framing of NIPT has reflected the set of ELSI considerations identified above or has highlighted other unique concerns. NIPT is still an emerging technology for prenatal screening and media portrayals, in interaction with other cultural forces, could play a pivotal role in shaping public perceptions and framing policy debates on integration of the test into clinical practice.

\section{Mass media and the framing of genetic testing}

The mass media constitute the primary sources of scientific and health information for the general public, as well as for scientists and physicians [Phillips et al., 1991]. Previous research has established that people routinely use media sources and rely on media professionals for information and interpretation on critical issues concerning innovation in science and technology, especially when they attempt to understand new and controversial science in ways that relate to their own lives and needs [Friedman, Dunwoody and Rogers, 1999]. In addition, the news media have tended to influence the public communication of scientific controversies through their ability to give legitimacy to certain opinions and perspectives, and also through the selective presentation of information to their audiences [Mazur, 1981]. Some notable examples of how news media frame the public discourse on controversial science and health issues include the AIDS crisis [Miller, Kitzinger and Williams, 1998], the stem cell controversy [Nisbet, Brossard and Kroepsch, 2003], and the debate on gene patenting [Caulfield, Bubela and Murdoch, 2007]. In those cases, media coverage has not only defined and amplified the underlying issues, but has also set the tone for public debate.

Although there is no evidence for direct impact of media messages on beliefs and behavior [Gauntlett, 1995] and the media "effects" model has failed to account for how media audiences develop their own critical and heterogeneous interpretations of media texts [Gauntlett, 2004], two interrelated processes in news media production - framing and agenda-setting provide an analytical framework to conceptualize and assess the impact of media messages on audiences and the public discourse in general. The concept of framing emphasizes the selective presentation in media coverage of specific topics, facts, controversies, actors, and assertions in news stories [Entman, 1993; Scheufele, 1999]. Entman [1993] has indicated that "to frame is to select some aspects of a perceived reality and make them more salient in a communicating text, in such a way as to promote a particular problem definition, causal interpretation, moral evaluation, and /or treatment recommendation" (p. 52). Frames are routinely used in news reporting to call attention to some aspects of reality while obscuring other elements [Entman, 1993]. Media organizations often "dramatize" news on a variety of subjects (i.e., use dramatic story lines or narratives) to increase their audience share [Nisbet, Brossard and Kroepsch, 2003]. Media framing research is an important paradigm in science communication studies that has moved away from traditional notions of "media effects" (e.g., media users' attitudes, beliefs, cognitions, or behaviors) and "media impact" (e.g., impact beyond individual media users at the systemic level 
of organizations) towards newer concepts of "media engagement," an analytical orientation that aims to grasp how media are used and cultural meanings are constructed by an active audience.

Most scientific news reports are routinely framed through the use of images, concepts and vocabulary that would make the information intriguing, relevant and comprehensible for mass audiences [Friedman, Dunwoody and Rogers, 1999]. The interpretive story lines used in media framing provide specific contexts for understanding the issues being presented and can significantly influence the audiences' perceptions by limiting the range of interpretations on complex topics. It is important to note that once an issue has been framed by the media in a particular light, public perception tends to remain stable over time [Nisbet, Brossard and Kroepsch, 2003]. This tendency is well exemplified by embryonic stem-cell research, which has been consistently represented through the general frame of "morality / ethics" since the early years of discovery and political controversy (1998-2001), with both sides of the debate using rhetorical devices under the category of morality/ethics to argue their specific position [Nisbet, Brossard and Kroepsch, 2003]. This dominant frame in the embryonic stem-cell debate has remained stable until 2010 when the focus of the news stories shifted towards issue-specific frames such as clinical translation and the potential of scientific discoveries in the field [Kamenova and Caulfield, 2015].

The agenda-setting theory provides a similar perspective on media effects. This approach has established that the main effect of news media is agenda-setting although media cannot make people think in a certain way, they can still influence what people think about by highlighting certain issues and excluding others from coverage [McCombs and Shaw, 1972]. Mass media, according to this model, plays a considerable role in setting the public policy agenda by making certain issues salient in the public domain, while marginalizing others. Previous research suggests that mass media have had an impact on the public understanding of genetic research and how policy debates on genetic testing were framed. News media coverage has been largely unbalanced - either emphasizing the negative consequences of genetics (e.g., insurance or employment discrimination, and the possibility of human genetic modification) and thus instilling fear in people, or misleading the public about the potential of genetic research for medicine [Geller, Bernhardt and Holtzman, 2002]. Studies have revealed a media tendency to present overly optimistic portrayals of the relevance of genetics to individual health and to exaggerate the potential health benefits of genetic testing - a phenomenon known as "genohype" [Caulfield, 2004; Holtzman, 1999; Bubela and Caulfield, 2004].

Media ability to influence people's health care choices regarding genetic testing is best exemplified by what has become known as the "Angelina Jolie Effect". This term was used in the popular press and in the scholarly literature to describe the impact of actress Angelina Jolie's disclosure in an op-ed piece in New York Times from May 14, 2013 that she carries a high-risk BCRA1 mutation and has chosen to undergo bilateral prophylactic mastectomy. Although Jolie's prophylactic mastectomy received unprecedented publicity and contributed to the salience of the issues of hereditary breast/ovarian cancer, the extended media coverage did not increase the public understanding of cancer risks and who should be tested for BRCA 1/2 mutations [Kamenova, Reshef and Caulfield, 2013; Borzekowski et al., 2013]. Rather, a considerable upsurge in requests for BRCA $1 / 2$ genetic testing was 
observed after her disclosure, particularly from individuals at low risk for hereditary breast/ovarian cancer [MacCuaig, 2014; Evans et al., 2014]. This case clearly highlights the impact of mass media on shaping the public discourse on health issues and influencing patients' demand for services.

\section{Objective}

While there is a fast growing body of academic literature that explores ethical, social and legal challenges presented by NIPT, the media discourse on the issue has not been sufficiently studied. One attempt is a recent analysis of press coverage on NIPT in the United Kingdom, which has shown predominantly positive reporting, with an emphasis on benefits rather than concerns and limitations [Lewis, Choudhury and Chitty, 2015]. This study is limited to publications on the issue in major U.K. print and digital newspapers only. In this article, we provide an in-depth perspective on the characteristics of media coverage across diverse media sources and different geographic regions, focusing on how the clinical readiness of NIPT was represented and what ethical and policy-related concerns were highlighted. We analyze the media discourse from January 1, 2013 to December 31, 2013 - a one-year period marked by a significant in-take of NIPT clinical services in North America, Europe, and the Asia-Pacific region, as well as a rapid growth of the global NIPT market [Transparency Market Research, 2015]. Given the emphasis on intellectual property (IP) and commercialization issues in the emerging debate on NIPT [Agarwal et al., 2013], we considered important to scrutinize how NIPT was portrayed in both the popular press and industry news publications. The major objective of our analysis of media coverage hence was to establish major themes and dominant frames in media representations across different news sources that may shed light on the social context of discourse on this controversial technology.

We conducted searches on the Factiva database, which provides an extensive archive of news and business information, including access to 1000 newspapers published internationally. We collected news reports on NIPT published in a variety of media sources from January 1, 2013 to December 31, 2013 using the following keywords: 'non-invasive prenatal' and at least one of the following words 'diagnostics' 'diagnosis,' 'testing,' or 'screening'. The search covered a broad range of print and online news sources, including print and online editions of newspapers, online newsletters, trade and industry newsletters, and newswires. After excluding duplicates, the search resulted in 307 reports in English-language newspapers, trade and industry newsletters, newswire services, and other miscellaneous sources (e.g. magazines, transcripts of news broadcast). We further sorted out 173 relevant articles by removing non-articles (e.g., content summaries, stock quotes) and articles that made only passing references to NIPT.

Although newswires are frequently omitted from media studies with the assumption that such media texts are not available to the general public, we included in our analysis those newswires that were actually run in online media. These news reports came from a variety of sources (e.g., PR newswire, NewsRx, Business Wire, Canada NewsWire, Reuters News) and were potentially accessible to non-specialist audiences. While we are unable to speculate about the actual impact of those sources on the public perceptions of NIPT, it was important to include all online publications since in recent years the Internet has become the first 
source of information for general health issues and health services for most people [Koch-Weser et al., 2010; Marrie et al., 2013].

Preliminary coding categories for a systematic content analysis were developed by the first author of the paper through an inductive-deductive process. This involved reading the entire dataset, identification of recurrent themes in the news reports, and their organization in structured codes. The draft coding frame (devised by the first author) was further refined by the second author, particularly by adding sub-themes to qualitative themes such as the perceived attributes of the test, ethical concerns, and policy considerations regarding the clinical use of NIPT, that have been articulated in the emerging scholarly literature on the issue. All authors read and agreed upon the final coding frame which included the following major coding categories: 1) frequencies of coverage by country; 2) patterns of reporting (e.g., publication source, article type, and author); 3) the perceived attributes of the test, particularly benefits and disadvantages associated with this technology; 4) specific ethical concerns and policy implications concerning the utilization of NIPT in the healthcare system; 5) how the commercial and patent landscape for NIPT was portrayed (e.g., whether NIPT was presented as a cost effective procedure, mentions of currently available NIPT for fetal aneuploidy, discussions of major companies and commercial and academic laboratories developing or marketing such tests, patent infringement and disputes); and 6) the major theme of the article. The coding of the articles was carried out by the third author and was then verified by the first author. All authors agreed on items that were characterized by ambiguity.

Framing research remains a methodologically contested area since "frame" appears to be a rather obscure and abstract variable that is difficult to operationalize, quantify, and code in systematic content analysis. Therefore, it was necessary to draw some analytical distinctions between "themes" and "frames" in order to select appropriate methodology for the current study. Following Entman's conceptualization of framing, we suggest that "themes" constitute distinct, unifying and central ideas that permeate the news stories, whereas "frames" are indicative of the relative salience of particular aspects and attributes of the topic. Framing involves a complex process of inclusion, exclusion and salience of certain features of content that can highlight certain interpretations, assertions and evaluations on the topic and this creates an overall theme for each news story. This definition further implies an important distinction between thematic and frame analysis of media content. While analysis of the major themes of news articles focuses exclusively on the manifest content of media coverage, framing research also allows to determine the latent content of media texts, that is, salient aspects of the topic excluded from coverage and news frames that are embedded within media. Our study initially utilized a thematic analysis to derive inductively key themes from the news stories on NIPT. Frame analysis was then undertaken to further assess how these coded themes link to salient news frames in the media discourse on emerging technologies in biomedicine. Using a deductive approach, we applied a generalizable typology of frames, which has been established by past research on media representations of controversies in science policy and biomedical science, to identify both general and emerging issue-specific frames in media representations of NIPT (e.g., scientific certainty about the reliability of NIPT as a testing tool). Our findings about the media framing of NIPT are further conceptualized in the discussion section. 
Textual content analysis is generally considered subjective as the coding process can be affected by the individual coder's subjective judgment and personal biases, particularly qualitative codes that require interpretive effort and evaluation. Therefore, inter-coder reliability assessment using Cohen's kappa $(\kappa)$ was conducted on the qualitative themes in the coding frame that could yield interpretive difference between coders. An independent researcher coding 10 percent of the news reports $(n=17)$. This researcher was introduced to the objectives of the study and the methods used to develop the coding frame. The analysis of the $\kappa$ scores, similarly to all other statistical analyses for the study, were performed with SPSS statistical software. As shown in Table 1, the $\kappa$ scores on key coding categories ranged between .759 and .879 , with a mean score of $\kappa=.830$ which indicates an almost perfect inter-rater agreement according to the benchmark standards for interpreting kappa $(\kappa)$ developed by Landis and Koch [Landis and Koch, 1977].

Table 1. Inter-rater reliability assessment on key variables.

\begin{tabular}{|lcc|}
\hline Coding frame question & $\kappa$ value & $\boldsymbol{n}$ of cases \\
\hline What benefits of NIPT were mentioned? & .759 & 17 \\
What is the major ethical concern associated with NIPT? & .879 & 17 \\
What is the major policy concern associated with NIPT? & .835 & 17 \\
What was the major theme of the article? & .848 & 17 \\
Mean kappa $(\kappa)$ score* & .830 & $\mathbf{1 7}$ \\
& \\
* Strength of agreement denoted by kappa $(\kappa):<0=$ poor, $.01-.20=$ slight, \\
$.21-.40=$ fair, $.41-.60=$ moderate, $.61-.80=$ substantial and $.81-1=$ almost perfect. \\
\hline
\end{tabular}

Our data indicated a continuous media interest in non-invasive prenatal testing in 2013, with more extensive coverage on the issue occurring during the months of January, April, June and November (see Figure 1 below). The articles we collected came from a variety of news sources. The following distribution occurred: $58.4 \%$ were articles from newswire services, $16 \%$ were published in trade and industry newsletters, $13.9 \%$ from print newspapers, $9.8 \%$ from online newspapers, $1.2 \%$ from magazines, and one transcript of news broadcast $(0.6 \%)$.

\section{Geographic distribution and NIPT providers}

Data on the distribution of news reports by country is presented in Table 2 below. Most articles came from US media sources. More than half of the articles (52\%) mentioned private companies providing NIPT services, with the most frequently mentioned being the Californian companies Natera Inc., Verinata Health Inc., and Ariosa Diagnostics Inc. as illustrated in Table 3.

\section{Benefits of NIPT}

Benefits of NIPT were discussed in 112 articles (64.6\% of the dataset). Two major benefits were articulated: 1 ) accuracy and reliability (67 articles, $38.7 \%)$; and 


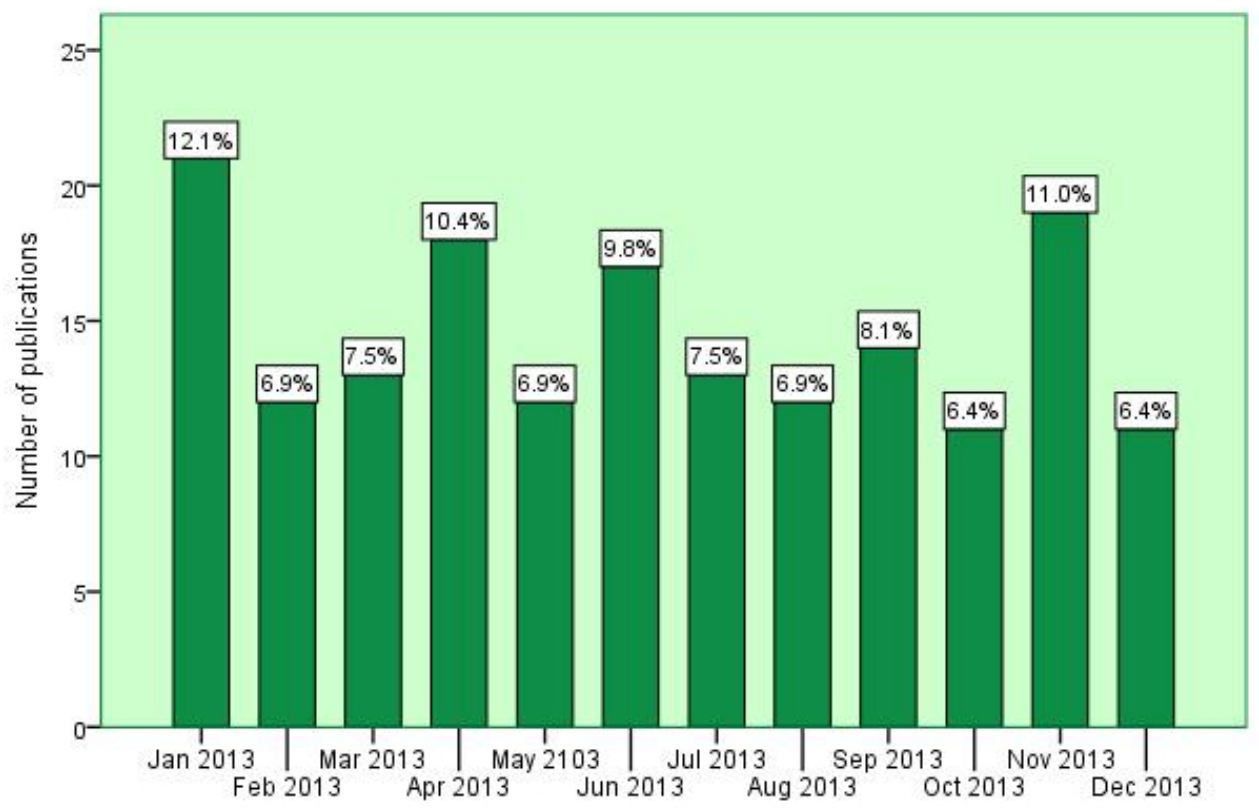

Figure 1. Frequency of news coverage $(n=173)$.

Table 2. Distribution of news reports by country.

\begin{tabular}{|lrr|}
\hline Country & $\begin{array}{r}\text { Number of } \\
\text { publications }\end{array}$ & $\begin{array}{r}\text { Percentage } \\
\text { in data set }\end{array}$ \\
\hline Canada & 7 & 4.0 \\
U.S.A. & 126 & 72.8 \\
U.K. & 10 & 5.8 \\
Australia & 7 & 4.0 \\
New Zealand & 2 & 1.2 \\
India & 9 & 5.2 \\
Singapore & 1 & 0.6 \\
UAE & 2 & 1.2 \\
South Korea & 1 & 0.6 \\
Jordan & 1 & 0.6 \\
Cyprus & 1 & 0.6 \\
China & 5 & 2.9 \\
Japan & 1 & 0.6 \\
\hline
\end{tabular}

2) safety (e.g., reduced risk to the fetus and for miscarriages) (53 articles, 30.6\%). Six additional advantages were emphasized, albeit to a lesser extent: 1 ) the benefit of reducing the need for amniocentesis (28 articles); 2 ) the possibility of informed choice at the earlier stages of pregnancy (16 articles); 3 ) the potential to detect effectively a wider range of genetic disorders ( 5 articles); 4 ) the general ease of testing process (11 articles); 5) psychological benefits, such as promoting peace of mind and facilitating early bonding with fetus ( 2 articles); and 6) cost effectiveness (2 articles).

We compared how the two major benefits were defined in different news sources. First, NIPT was presented as a "highly accurate and reliable" testing method in $37.5 \%$ of all print newspaper reports; in $23.5 \%$ of the online newspaper reports; in 
Table 3. Mentions of major NIPT companies.

\begin{tabular}{|lrr|}
\hline Country & $\begin{array}{r}\text { Number of } \\
\text { publications }\end{array}$ & $\begin{array}{r}\text { Percentage } \\
\text { in data set }\end{array}$ \\
\hline Sequenom & 6 & 3.5 \\
Verinata Health & 23 & 13.3 \\
Ariosa Diagnostics & 15 & 8.7 \\
Natera & 27 & 15.6 \\
BGI Health & 3 & 1.7 \\
LifeCodexx & 1 & 0.6 \\
Other & 6 & 3.5 \\
Multiple companies & 9 & 5.2 \\
\hline
\end{tabular}

$21.4 \%$ of the articles in trade and industry newsletters; and in $25.7 \%$ of all newswires. Second, NIPT was characterized as a safer testing method in $25 \%$ of all print newspaper reports; in $35.3 \%$ of the online newspaper reports; in $25 \%$ of the articles in trade and industry newsletters; and in $18.8 \%$ of all newswires.

\section{Disadvantages of NIPT}

There were very limited discussions of disadvantages associated with attributes of the test. Interestingly, 156 news reports $(90.2 \%)$ did not mention any negatives associated with NIPT. Concerns that the test will increase anxiety amongst pregnant women were expressed in 5 articles. Another 6 articles indicated that it could increase pressure on pregnant women to terminate if results were positive for fetal chromosome abnormalities. Furthermore, 2 news reports pointed to difficulties in explaining and understanding what testing was for; 5 articles were concerned that NIPT may put less emphasis on consent due to the absence of risk and routinization of the procedure; 3 articles mentioned that the ease of the test may reduce thought before taking the test; one article indicated that NIPT can increase connection to fetus in the earliest stages in cases when pregnancy might be terminated for medical reasons; and another one stated it might increase the need for genetic counseling.

\section{Ethical concerns}

Only 22 news reports (12.9\%) discussed ethical concerns associated with NIPT. For example, 8 reports stated that NIPT could potentially diminish the perceived value of lives of those who are disabled; 5 reports that it could increase the number of terminated pregnancies; 5 reports that it could become normalized and offered as "routine" and thus undermine the process of informed consent; 3 reports that it could be used for (non-medical) fetal sex determination and selection; and 2 reports that it could have potential eugenic implications (e.g., terminating pregnancies based on non-medical characteristics).

The possibility that NIPT could diminish the perceived value of lives of those who are disabled was defined as the major ethical issue in $25 \%$ of the print newspaper reports, in one online newspaper publication, and in one newswire. The potential of NIPT to increase the number of terminated pregnancies was the major ethical 
issue in $8.3 \%$ of the print newspaper reports, in one online newspaper publication, and in one newswire. Three articles identified the potential use of NIPT for fetal sex determination and selection, and three emphasized that NIPT could be normalized and offered as a routine test. Eugenic implications were seen as the primary ethical issue in 2 articles (an online newspaper publication and a news broadcast transcript).

\section{Policy implications}

Policy implications related to the utilization of NIPT in clinical practice were addressed in 19 articles (11\%). Concerns that NIPT should be offered with the provision of pre-test and post-test counselling were expressed in 8 articles, while 5 emphasized coverage by health insurance plans as a key issue. By contrast, another 3 expressed the opinion that NIPT did not raise new policy and social concerns, but rather constituted an extension of the existing debate. One report stated that NIPT should not be offered as a DTC (direct-to-consumer) test without professional health input and one stated the need to develop guidelines for providing patients with information.

\section{Major themes}

Figure 2 below shows the most prominent themes featured in the news reports on NIPT.

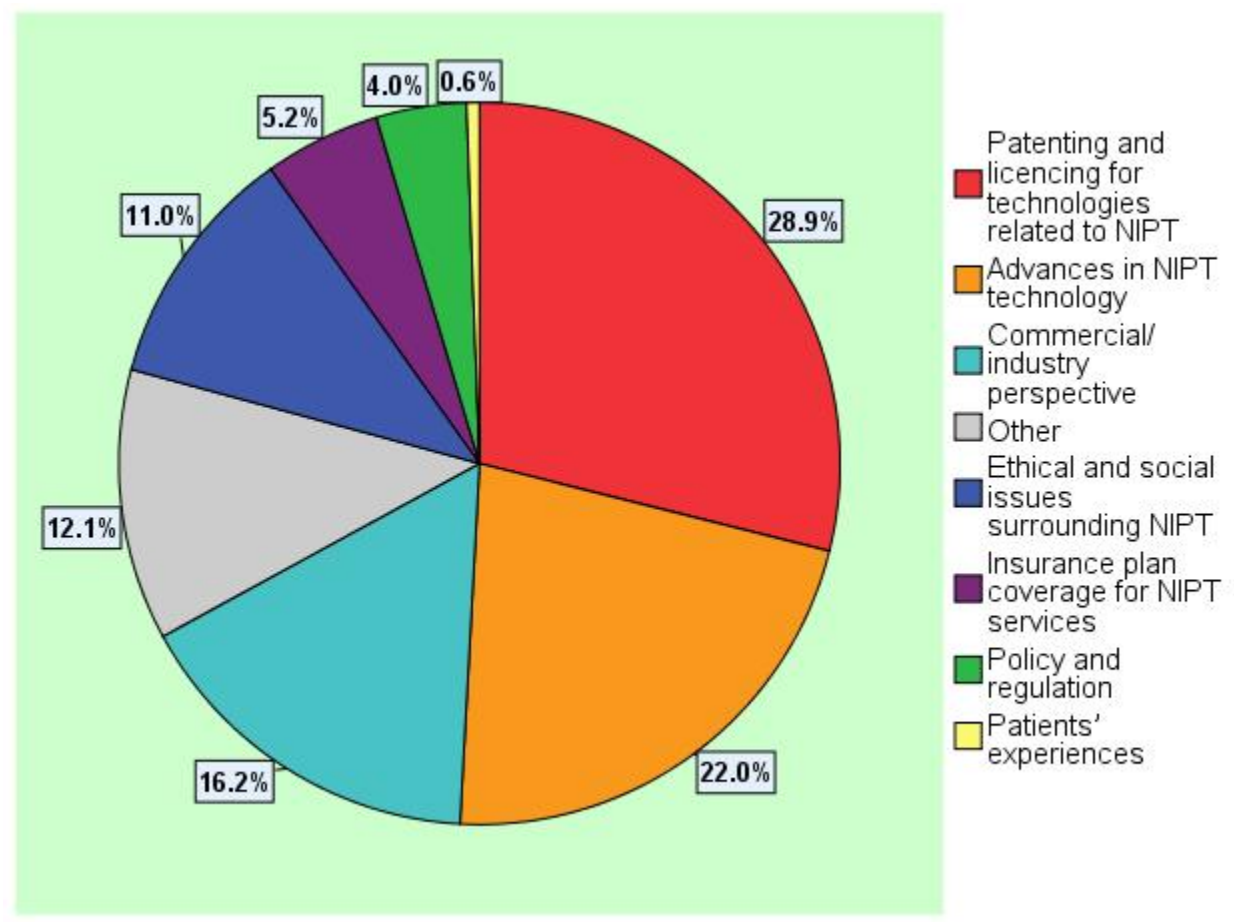

Figure 2. Major themes in the news media portrayal of NIPT.

Topics that were categorized as "other" include: general overview of NIPT (8 reports); the use of NIPT in obstetrics (3 reports); research funding (5 reports); 
contributions of leading scientists (3 reports); cost effectiveness of NIPT (1 report); and evaluation of invasive vs. non-invasive testing (1 report).

Since patenting and licensing of NIPT appeared to be the most prominent issue in news coverage, we further assessed the themes of the 50 articles that reported exclusively on this topic. Individual patent applications were the central theme of 11 articles. Interestingly, these articles simply reported that an application had been filed and did not elaborate on the ramifications. Rather, the majority of these articles included large citations taken from the application itself. Similarly, two articles were simple reports of a patent being granted. In a similar fashion, 30 articles were reports on licensing agreements for specific geographic areas (usually countries, but sometimes regions) between localized laboratories and major NIPT companies (e.g., Natera, BGI, Illumina). Three news reports mentioned possible patentability of a new technology related to NIPT. Four of the articles summarized or reported on specific patent cases between the major labs. Each of these articles mentioned the US Supreme Court decision in Association for Molecular Pathology v. Myriad Genetics (569 US 12-398, 2013), but they did not provide background discussions on the gene patenting controversy.

\section{Who was cited in the news}

We found out that $50.9 \%$ of the news reports provided references to expert and stakeholder opinion. A range of people and levels of expertise were cited on issues concerning NIPT including: industry representatives (32.4\%), academic, scientific, and legal experts $(16.2 \%)$, health professionals $(8.6 \%)$, patients $(3.5 \%)$, government officials (2.4\%), and disability advocates (1.7\%).

Our data show that NIPT was favorably portrayed across all news sources under consideration. There was a strong emphasis on the benefits of this technology and only minimal reporting on potential negative implications. In fact, the majority of news reports did not mention any negatives or uncertainty associated with this type of genetic tests. The positive portrayal of NIPT is by no means surprising, given the media hype surrounding the emerging technologies in genetics and genomics. As previous studies have shown, media representations have consistently overemphasized benefits, while overlooking risks and the experimental nature of these technologies [Caulfield, 2004; Bubela and Caulfield, 2004]. Furthermore, longitudinal studies have shown a general positive bias in media framing of human biotechnologies vis-à-vis agricultural biotechnologies [Marks et al., 2007].

Overall, NIPT was characterized in the news stories as highly accurate and a much safer testing option in comparison to prenatal screening or diagnostic tests that are currently standard of practice. The news reports also emphasized, to a lesser extent, that NIPT could potentially eliminate the need for amniocentesis, a procedure that entails an increased risk of miscarriage, and that it can provide pregnant women with informed choice at the earlier stages of pregnancy. Interestingly, the publications in print newspapers that we analyzed placed a greater emphasis on the accuracy and reliability of NIPT in comparison to the other 
news sources. Given the limited number of newspaper articles in our dataset, however, it is difficult to generalize this finding.

When assessing this predominantly positive media portrayal, it is important to note that NIPT is an emerging technology that has not yet been established as a diagnostic tool for any condition. While there is evidence that the accuracy of classification of autosomal aneuploidy by NIPT is high [Tiller et al., 2015], all professional guidelines currently require that NIPT results are confirmed with invasive testing before a pregnant woman makes a termination decision. NIPT has mainly been utilized as a screening method for women identified as high-risk (e.g., as a second-tier screening test), and it is just presently being introduced for screening of women with average-risk (e.g., as a first-tier screening test replacing current screening). When this is taken into account, the emphasis on accuracy in media coverage constitutes an overstatement of the clinical readiness and value of NIPT.

Nonetheless, the media portrayal of NIPT as somewhat superior to other prenatal screening methods appears consistent with public perceptions and attitudes in some countries. As shown in a recent study of attitudes of pregnant women and their male partners using focus groups and interviews, both low and high risk pregnant women considered early testing such as NIPT more advantageous than current prenatal screening, emphasizing its accuracy, safety and the potential to lower the barrier for testing [van Schendel et al., 2014]. Yet, it is worth noting that public acceptance is not unconditional as the study participants also argued that NIPT should not be widely and uncritically used, but rather should be limited to screening for severe disorders [van Schendel et al., 2014].

Surprisingly, ethical concerns arising from the use of NIPT and its integration in the clinical practice were not at the center of media coverage. In fact, the majority of news reports did not mention any ethical concerns at all. It is important to further contextualize this finding in reference to previous studies of media representations of biomedical science and the emerging technologies. Following the generalizable typology of frames initially developed by Gamson and Modigliani (1989) in their analysis of media discourse on nuclear power [Gamson and Modigliani, 1989], media framing research has established that the 'ethics/morality' frame had consistently reappeared in media coverage and policy debates on past controversies in biotechnology and biomedical science [Durant, Bauer and Gaskell, 1998; Nisbet and Lewenstein, 2002; Nisbet, 2010]. These studies have identified eight generic frames that had been used to define science-related issues: social progress; economic development/competiveness; morality/ethics; scientific/technical uncertainty; Pandora's box/Frankenstein's monster/runaway science; public accountability/governance; midway/alternative path; and conflict/strategy [Nisbet, 2010]. These general interpretive frames provide context for arguments and interpretations between opposing sides in the debate, as well as the emergence of unique issue-specific frames. When the results of our content analysis are placed in the context of a such generalizable typology, the frames of "social progress" and "scientific/technical uncertainty," rather than the "ethics/morality" frame, appeared central to media representations of NIPT, with emerging issue-specific frames emphasizing the medical benefits of the test and its accuracy (e.g., scientific certainty about the reliability of NIPT as a testing tool). 
Similarly, social implications and policy concerns regarding the integration of NIPT into prenatal care were rarely addressed. We found out that two major policy issues that were more prominently articulated: 1 ) the need to offer NIPT with the provision of pre-test and post-test counseling, and 2) NIPT coverage by health insurance plans. A plausible explanation for limited discussions of ethical and policy concerns in media coverage is that issues associated with NIPT have not yet received salience in "elite" newspapers, which are renowned for their high-quality reporting, authoritative discussions of health and science topics, and authoritative comment on economic, political, social, and ethical issues [Lehman-Wilzig and Seletzky, 2012]. Indeed, our analysis has shown a very limited volume of coverage on NIPT in major newspapers - only $13.9 \%$ of the articles came from such media sources.

There are certain limitations to this study should be noted, specifically the small number of publications in certain media types such as print and online newspapers. The small sample of articles from these media sources precludes any generalizations about recurrent themes and dominant frames. Subsequently, it was difficult to establish a nuanced perspective on similarities and differences between representations and framing across all different news sources that we analyzed. Therefore, we can only speculate as to whether our finding of a greater focus on ethical issues surrounding NIPT in print newspaper articles included in our dataset is indeed indicative of a more general trend in framing the technology in those media sources. The larger study samples in other media categories, however, have allowed us to draw some interesting comparisons as to how NIPT was framed. Not surprisingly, publications in trade and industry newsletters have largely neglected ethical issues, and the focus of coverage was primarily on issues arising from the commercialization of NIPT services (e.g., patents and licensing agreements for specific geographic regions). The newswires, which comprise slightly over $50 \%$ of the data set, have included diverse themes, with a greater focus on advances in NIPT technologies, patenting and licensing, and industry-related news. There was limited reporting on ethical issues and policy concerns in these sources as well. Many of these articles came from online newsweeklies, such as Medicine and Health Weekly, Obesity, Fitness and Wellness Weekly, Life Science Weekly, and Women's Health Weekly, published by NewsRx - a media company producing digital media, printed media, and news services. The company is the largest producer and distributor of online health news and its 194 newsweeklies in health and other fields are distributed to subscribers and partners such as Factiva, LexisNexis, and the Wall Street Journal Professional Edition.

There is presently a highly lucrative global market for NIPT and its development has been largely driven by industry. In the current context, the predominant media framing of NIPT around the medical benefits of the test and commercialization issues such patenting and licensing, while overlooking key ethical and policy concerns, seems to reflect the realities in the field. Indeed, our analysis reveals that the emerging industry has acquired strong visibility in the media discourse and industry representatives were frequently cited in the news reports. At the same time, the news rarely included perspectives of health professionals and pregnant women who are the end users of the technology. 
Overall, our content analysis has established that news media have not hesitated to frame NIPT in a positive light by emphasizing its accuracy for early detection of chromosomal aneuploidies, safety, and potential as a diagnostic tool. The ethics of NIPT, however, was rarely addressed in the news stories, which points to an important dimension missing in the media discourse on this emerging technology. Mass media - through its agenda-setting and framing functions - has the potential to shape public and policy debates on the emerging technologies in biomedicine. The "hyping" of benefits in the news media coverage, while overlooking ethical and policy-related concerns, as well as patients' experiences, may have an impact on the public understanding of NIPT and the framing of key issues for policy debate.

Acknowledgments The authors thank Frances Wallace from the University of Alberta and Hazar Haidar and Charles Dupras from the University of Montreal for assistance with research. This study was completed under the PEGASUS (PErsonalized Genomics for prenatal Aneuploidy Screening USing maternal blood) grant, funded by Genome Canada, Genome Quebec, Genome Alberta, and the Canadian Institutes for Health Research (CIHR) and under the PACEOMICS (Personalized, Accessible, Cost-Effective applications of 'Omics technologies) grant, funded by Genome Canada, Genome Alberta, CIHR, and Alberta Health \& Wellness.

\section{References}

Agarwal, A., Sayres, L. C., Cho, M. K., Cook-Deegan, R. and Chandrasekharan, S. (2013). 'Commercial landscape of noninvasive prenatal testing in the United States'. Prenatal Diagnosis 33 (6), pp. 521-531. DOI: 10.1002/pd.4101. PMID: 23686656.

Beulen, L., Grutters, J. P. C., Faas, B. H., Feenstra, I., van Vugt, J. M. G. and Bekker, M. N. (2014). 'The consequences of implementing non-invasive prenatal testing in Dutch national health care: a cost-effectiveness analysis'. European Journal of Obstetrics, Gynecology and Reproductive Biology 182, pp. 53-61. DOI: 10.1016/j.e jogrb.2014.08.028. PMID: 25238658.

Bianchi, D. W., Platt, L. D., Goldberg, J. D., Abuhamad, A. Z., Sehnert, A. J. and Rava, R. P. 'Genome-wide fetal aneuploidy detection by maternal plasma DNA sequencing'. Obstetrics and Gynecology 119 (5), pp. 890-901. DOI: 10.1097/AOG. 0b013e31824fb482.

Borzekowski, D. L. G., Guan, Y., Smith, K. C., Erby, L. H. and Roter, D. L. (2013). 'The Angelina effect: immediate reach, grasp, and impact of going public'. Genetics in Medicine 16 (7), pp. 516-521. DOI: 10.1038/gim. 2013.181. PMID: 24357847.

Bubela, T. M. and Caulfield, T. A. (2004). 'Do the print media "hype" genetic research? A comparison of newspaper stories and peer-reviewed research papers'. Canadian Medical Association journal 170 (9), pp. 1399-1407. PMID: 15111473.

Caulfield, T. (2004). 'Biotechnology and the popular press: hype and the selling of science'. Trends in Biotechnology 22 (7), pp. 337-339. DOI: 10.1016/j.tibtech. 2004.03.014. PMID: 15245905.

- (2014). 'Easy Test. Tough Answer'. Policy Options, March-April, pp. 8-9.

Caulfield, T., Bubela, T. and Murdoch, C. J. (2007). 'Myriad and the mass media: the covering of a gene patent controversy'. Genetics in Medicine 9 (12), pp. 850-855. DOI: 10.1097/GIM. 0b013e31815bf965. PMID: 18091435. 
Children's Hospital of Eastern Ontario (CHEO) (2014). Frequently Asked Questions: Non-invasive prenatal testing (NIPT). URL: http://www. cheo.on.ca/en/NIPT (visited on 11th December 2014).

Chitty, L. S. and Bianchi, D. W. (2013). 'Noninvasive prenatal testing: the paradigm is shifting rapidly'. Prenatal Diagnosis 33 (6), pp. 511-513. DOI: 10.1002/pd.4136. PMID: 23686654.

Deans, Z. and Newson, A. J. (2011). 'Should non-invasiveness change informed consent procedures for prenatal diagnosis?' Health care analysis 19 (2), pp. 122-132. DOI: 10.1007/s10728-010-0146-8. PMID: 20217481.

Dickens, B. M. (2014). 'Ethical and legal aspects of noninvasive prenatal genetic diagnosis'. International Journal of Gynaecology and Obstetrics 124 (2), pp. 181-184. DOI: 10.1016/j.ijgo.2013.11.001. PMID: 24299974.

Durant, J., Bauer, M. W. and Gaskell, G. (1998). Biotechnology in the Public Sphere: A European Sourcebook. Lansing, MI, U.S.A.: Michigan State University Press.

Entman, R. M. (1993). 'Framing: Toward Clarification of a Fractured Paradigm'. Journal of Communication 43 (4), pp. 51-58. DOI: 10.1111/j.1460-2466.1993.tb01304.x.

Evans, D. G., Barwell, J., Eccles, D. M., Collins, A., Izatt, L., Jacobs, C., Donaldson, A., Brady, A. F., Cuthbert, A., Harrison, R., Thomas, S., Howell, A., FH02 Study Group, RGC teams, Miedzybrodzka, Z. and Murray, A. (2014). 'The Angelina Jolie effect: how high celebrity profile can have a major impact on provision of cancer related services'. Breast cancer research 16 (5), p. 442. DOI: 10.1186/s13058-014-0442-6. PMID: 25510853.

Fan, H. C., Gu, W., Wang, J., Blumenfeld, Y. J., El-Sayed, Y. Y. and Quake, S. R. (2012). 'Non-invasive prenatal measurement of the fetal genome'. Nature 487 (7407), pp. 320-324. DOI: 10.1038/nature11251. PMID: 22763444.

Friedman, S. M., Dunwoody, S. and Rogers, C. L., eds. (1999). Communicating uncertainty: media coverage of new and controversial science. Mahwah, NJ, U.S.A.: Lawrence Erlbaum Associate.

Gamson, W. A. and Modigliani, A. (1989). 'Media Discourse and Public Opinion on Nuclear Power: A Constructionist Approach'. American Journal of Sociology 95 (1), pp. 1-37. URL: http://www. jstor .org/stable/2780405.

Gauntlett, D. (1995). Moving experiences: understanding television's influences and effects. London, U.K.: John Libbey.

- (2004). 'Ten Things Wrong with The "Effects Model'. In: Media studies: the essential resource. Ed. by P. Rayner, P. Wall and S. Kruger. London, U.K.: Routledge.

Geller, G., Bernhardt, B. A. and Holtzman, N. A. (2002). 'The media and public reaction to genetic research'. JAMA 287 (6), p. 773. PMID: 11851549.

George, S. M. (2006). 'Millions of missing girls: from fetal sexing to high technology sex selection in India'. Prenatal Diagnosis 26 (7), pp. 604-609. DOI: 10.1002/pd.1475. PMID: 16856224.

Greely, H. T. (2011). 'Get ready for the flood of fetal gene screening'. Nature 469 (7330), pp. 289-291. DOI: 10.1038/469289a. PMID: 21248817.

Hill, M., Karunaratna, M., Lewis, C., Forya, F. and Chitty, L. (2013). 'Views and preferences for the implementation of non-invasive prenatal diagnosis for single gene disorders from health professionals in the United Kingdom'. American Journal of Medical Genetics. Part A 161A (7), pp. 1612-1618. DOI: 10.1002/ajmg.a.35972. PMID: 23696422.

Holtzman, N. A. (1999). 'Are genetic tests adequately regulated?' Science 286 (5439), p. 409. PMID: 10577197. 
Kamenova, K. and Caulfield, T. (2015). 'Stem cell hype: media portrayal of therapy translation'. Science Translational Medicine 7 (278), 278ps4. DOI: 10.1126/scitranslmed.3010496. PMID: 25761887.

Kamenova, K., Reshef, A. and Caulfield, T. (2013). 'Angelina Jolie's faulty gene: newspaper coverage of a celebrity's preventive bilateral mastectomy in Canada, the United States, and the United Kingdom'. Genetics in Medicine 16 (7), pp. 522-528. DOI: 10.1038/gim. 2013.199. PMID: 24357851.

Kaposy, C. (2013). 'A disability critique of the new prenatal test for Down syndrome'. Kennedy Institute of Ethics Journal 23 (4), pp. 299-324. PMID: 24552074.

Kellogg, G., Slattery, L., Hudgins, L. and Ormond, K. (2014). 'Attitudes of mothers of children with down syndrome towards noninvasive prenatal testing'. Journal of Genetic Counseling 23 (5), pp. 805-813. DOI: 10.1007/s10897-014-9694-7. PMID: 24481673.

King, J. S. (2011). 'And genetic testing for all... The coming revolution in non-invasive prenatal genetic testing'. Rutgers Law Journal 42, pp. 599-658.

- (2012). 'Genetic tests: Politics and fetal diagnostics collide'. Nature 491 (7422), pp. 33-34. DOI: 10.1038/491033a. PMID: 23128210.

Kitzman, J. O., Snyder, M. W., Ventura, M., Lewis, A. P., Qiu, R., Simmons, L. E., Gammill, H. S., Rubens, C. E., Santillan, D. A., Murray, J. C., Tabor, H. K., Bamshad, M. J., Eichler, E. E. and Shendure, J. (2012). 'Noninvasive whole-genome sequencing of a human fetus'. Science Translational Medicine 4 (137), 137ra76. DOI: 10.1126/scitranslmed.3004323. PMID: 22674554.

Koch-Weser, S., Bradshaw, Y. S., Gualtieri, L. and Gallagher, S. S. (2010). 'The Internet as a health information source: findings from the 2007 Health Information National Trends Survey and implications for health communication'. Journal of Health Communication 15 Suppl 3, pp. 279-293. DOI: 10.1080/10810730.2010.522700. PMID: 21154099.

Landis, J. R. and Koch, G. G. (1977). 'The Measurement of Observer Agreement for Categorical Data'. Biometrics 33 (1), pp. 159-174. DOI: 10.2307/2529310.

Langlois, S., Brock, J.-A., Wilson, R. D., Audibert, F., Carroll, J., Cartier, L., Gagnon, A., Johnson, J.-A., Macdonald, W., Murphy-Kaulbeck, L., Okun, N., Pastuck, M., Senikas, V. and Genetics Committee (2013). 'Current status in non-invasive prenatal detection of Down syndrome, trisomy 18, and trisomy 13 using cell-free DNA in maternal plasma'. Journal of obstetrics and gynaecology Canada 35 (2), pp. 177-183. PMID: 23470070.

Lehman-Wilzig, S. and Seletzky, M. (2012). 'Elite and Popular Newspaper Publication of Press Releases: Differential Success Factors?' Public Relations Journal 6, p. 125.

Levine, B. A. and Goldschlag, D. (2014). Noninvasive Prenatal Testing: A New Standard of Care? URL: http: // contemporaryobgyn .modernmedicine.com/conte mporary-obgyn/content/tags/ariosa-diagnostics/noninvasive-prenataltesting-new-standard-care-0?page $=$ full (visited on 11th December 2014).

Lewis, C., Silcock, C. and Chitty, L. S. (2013). 'Non-invasive prenatal testing for Down's syndrome: pregnant women's views and likely uptake'. Public Health Genomics 16 (5), pp. 223-232. DOI: 10.1159/000353523. PMID: 23886854.

Lewis, C., Choudhury, M. and Chitty, L. S. (2015). "Hope for safe prenatal gene tests'. A content analysis of how the UK press media are reporting advances in non-invasive prenatal testing'. Prenatal Diagnosis 35 (5), pp. 420-427. DOI: 10.1002/pd.4488. PMID: 25233815. 
MacCuaig, M. (2014). 'The Angelina Jolie Effect: Assessing the Impact of a Celebrity's Story on Cancer Genetic Counseling'. Master's thesis. Brandeis University, U.S.A. URL: https://bir . brandeis . edu/handle/10192/27243.

Marks, L. A., Kalaitzandonakes, N., Wilkins, L. and Zakharova, L. (2007). 'Mass media framing of biotechnology news'. Public Understanding of Science 16 (2), pp. 183-203. DOI: 10.1177/0963662506065054.

Marrie, R. A., Salter, A. R., Tyry, T., Fox, R. J. and Cutter, G. R. (2013). ‘Preferred sources of health information in persons with multiple sclerosis: degree of trust and information sought'. Journal of Medical Internet Research 15 (4), e67. DOI: 10.2196/jmir.2466. PMID: 23635393.

Mazur, A. (1981). 'Media Coverage and Public Opinion on Scientific Controversies'. Journal of Communication 31 (2), pp. 106-115. DOI: 10.1111/j.1460-2466.1981.tb01234.x.

McCombs, M. E. and Shaw, D. L. (1972). 'The Agenda-Setting Function of Mass Media'. Public Opinion Quarterly 36 (2), pp. 176-187. DOI: 10.1086/267990.

Miller, D., Kitzinger, J. and Williams, K. (1998). The circuit of mass communication: media strategies, representation and audience reception in the AIDS crisis. London, U.K.: Sage Publications.

Morain, S., Greene, M. F. and Mello, M. M. (2013). 'A New Era in Noninvasive Prenatal Testing'. New England Journal of Medicine 369 (6), pp. 499-501. DOI: 10.1056/NEJMp1304843. PMID: 23862975.

Nisbet, M. C. (2010). 'Framing Science: A New Paradigm in Public Engagement'. In: Communicating Science: New Agendas in Communication. Ed. by L. Kahlor and P. Stout. New York, U.S.A.: Routledge, pp. 41-67.

Nisbet, M. C., Brossard, D. and Kroepsch, A. (2003). 'Framing science: the stem cell controversy in an age of press/politics'. The International Journal of Press/Politics 8 (2), pp. 36-70. DOI: $10.1177 / 1081180 \mathrm{X} 02251047$.

Nisbet, M. C. and Lewenstein, B. V. (2002). 'Biotechnology and the American Media The Policy Process and the Elite Press, 1970 to 1999'. Science Communication 23 (4), pp. 359-391. DOI: 10.1177/107554700202300401.

Norton, M. E., Rose, N. C. and Benn, P. (2013). ‘Noninvasive prenatal testing for fetal aneuploidy: clinical assessment and a plea for restraint'. Obstetrics and Gynecology 121 (4), pp. 847-850. DOI: 10.1097/AOG . 0b013e31828642c6. PMID: 23635685.

Oepkes, D., Yaron, Y., Kozlowski, P., Sousa, M. J. Rego de, Bartha, J. L., van den Akker, E. S., Dornan, S. M., Krampl-Bettelheim, E., Schmid, M., Wielgos, M., Cirigliano, V., Di Renzo, G. C., Cameron, A., Calda, P. and Tabor, A. (2014). 'Counseling for non-invasive prenatal testing (NIPT): what pregnant women may want to know'. Ultrasound in Obstetrics $\mathcal{E}$ Gynecology 44 (1), pp. 1-5. DOI: 10.1002/uog. 13394. PMID: 24984969.

Parens, E. and Asch, A. (1999). 'Special Supplement: The Disability Rights Critique of Prenatal Genetic Testing Reflections and Recommendations'. The Hastings Center Report 29 (5), S1-S22. DOI: 10.2307/3527746.

Perinatal Services BC (2014). Non-Invasive Prenatal testing (NIPT): A New Screening Option in BC. URL:

http://www. perinatalservicesbc.ca/ScreeningPrograms/PrenatalGeneticS creening/healthcare-providers/NonInvasivePrenatalTesting/default.htm (visited on 11th December 2014). 
Phillips, D. P., Kanter, E. J., Bednarczyk, B. and Tastad, P. L. (1991). 'Importance of the lay press in the transmission of medical knowledge to the scientific community'. The New England Journal of Medicine 325 (16), pp. 1180-1183. DOI: 10.1056/NEJM199110173251620. PMID: 1891034.

Scheufele, D. (1999). 'Framing as a theory of media effects'. Journal of Communication 49 (1), pp. 103-122. DOI: 10.1111/j.1460-2466.1999.tb02784.x.

Seavilleklein, V. (2009). 'Challenging the rhetoric of choice in prenatal screening'. Bioethics 23 (1), pp. 68-77. DOI: 10.1111/j.1467-8519.2008.00674.x. PMID: 19076943.

Skirton, H. and Patch, C. (2013). 'Factors affecting the clinical use of non-invasive prenatal testing: a mixed methods systematic review'. Prenatal Diagnosis 33 (6), pp. 532-541. PMID: 23828950.

Song, K., Musci, T. J. and Caughey, A. B. (2013). 'Clinical utility and cost of non-invasive prenatal testing with cfDNA analysis in high-risk women based on a US population'. The Journal of Maternal-Fetal $\mathcal{E}$ Neonatal Medicine 26 (12), pp. 1180-1185. DOI: 10.3109/14767058.2013.770464. PMID: 23356557.

Tiller, G. E., Kershberg, H. B., Goff, J., Coffeen, C., Liao, W. and Sehnert, A. J. (2015). 'Women's views and the impact of noninvasive prenatal testing on procedures in a managed care setting'. Prenatal Diagnosis 35 (5), pp. 428-433. DOI: 10.1002/pd . 4495. PMID: 25201151.

Toews, M. and Caulfield, T. (2014). 'Physician liability and non-invasive prenatal testing'. Journal of obstetrics and gynaecology Canada 36 (10), pp. 907-914. PMID: 25375305.

Transparency Market Research (2015). Non-invasive Prenatal Testing (NIPT) Market (BambniTest, Harmony, informaSeq, MaterniT21 PLUS, NIFTY, Panorama, PrenaTest, verifi, VisibiliT and Others) - Global Industry Analysis, Size, Volume, Share, Growth, Trends and Forecast 2014-2022. URL: http://www. transparencyma rketresearch.com/noninvasive-prenatal-diagnostics-market.html (visited on 19th February 2015).

van den Heuvel, A., Chitty, L., Dormandy, E., Newson, A., Deans, Z., Attwood, S., Haynes, S. and Marteau, T. M. (2010). 'Will the introduction of non-invasive prenatal diagnostic testing erode informed choices? An experimental study of health care professionals'. Patient Education and Counseling 78 (1), pp. 24-28. DOI: 10.1016/j.pec. 2009.05.014. PMID: 19560305.

van Schendel, R. V., Kleinveld, J. H., Dondorp, W. J., Pajkrt, E., Timmermans, D. R. M., Holtkamp, K. C. A., Karsten, M., Vlietstra, A. L., Lachmeijer, A. M. A. and Henneman, L. (2014). 'Attitudes of pregnant women and male partners towards non-invasive prenatal testing and widening the scope of prenatal screening'. European journal of human genetics 22 (12), pp. 1345-1350. DOI: 10.1038/ejhg. 2014.32. PMID: 24642832.

Wertz, D. C. and Fletcher, J. C. (1993). 'Prenatal diagnosis and sex selection in 19 nations'. Social Science \& Medicine 37 (11), pp. 1359-1366. PMID: 8284703.

Wilson, K. L., Czerwinski, J. L., Hoskovec, J. M., Noblin, S. J., Sullivan, C. M., Harbison, A., Campion, M. W., Devary, K., Devers, P. and Singletary, C. N. (2013). 'NSGC practice guideline: prenatal screening and diagnostic testing options for chromosome aneuploidy'. Journal of Genetic Counseling 22 (1), pp. 4-15. DOI: 10.1007/s10897-012-9545-3. PMID: 23179172. 
Dr. Kalina Kamenova is Assistant Professor at the Bachelor of Arts and Science Program at Trent University. Her research focuses on science communication, science policy, and the ethical, legal and social issues arising from new and emerging technologies in biomedicine. E-mail: kalinakamenova@trentu.ca.

Dr. Vardit Ravitsky is Associate Professor in Bioethics at the School of Public Health of the University of Montreal. Her research focuses on the ethical and social implications of reproductive technologies as well as genetics/genomics in the context of both research and clinical implementation.

E-mail: vardit.ravitsky@umontreal.ca.

Spencer McMullin is a JD student at the Faculty of Law of the University of Alberta. His research is situated at the intersection of health law and bioethics. E-mail: spencermcmullin@gmail.com.

Timothy Caulfield is Canada Research Chair in Health Law and Policy and Professor at the Faculty of Law and School of Public Health of the University of Alberta. He is a Fellow of the Trudeau Foundation and the Principal Investigator for a number of large interdisciplinary projects in the health sciences.

E-mail: caulfield@ualberta.ca.

\section{How to cite}

Kamenova, K., Ravitsky, V., McMullin, D. and Caulfield, T. (2016). 'Media portrayal of non-invasive prenatal testing: a missing ethical dimension'. JCOM 15(02), A03. 